\title{
An Analysis for Magnesium Alloy Curvature Products Formed by Staggered Extrusion (SE) Based on the Upper Bound Method
}

\section{Xi Jie Zhang}

Harbin University of Science and Technology

\section{Feng Li ( $\nabla$ fli@hrbust.edu.cn )}

Harbin University of Science and Technology

\section{Ye Wang}

Harbin University of Science and Technology

\section{Zi Yu Chen}

Harbin University of Science and Technology

\section{Research Article}

Keywords: Magnesium alloy, Staggered extrusion (SE), Upper bound method, Velocity fields, Experimental verification

Posted Date: May 17th, 2021

DOl: https://doi.org/10.21203/rs.3.rs-513729/v1

License: (c) (i) This work is licensed under a Creative Commons Attribution 4.0 International License. Read Full License

Version of Record: A version of this preprint was published at The International Journal of Advanced Manufacturing Technology on October 29th, 2021. See the published version at https://doi.org/10.1007/s00170-021-08167-z. 


\title{
An analysis for magnesium alloy curvature products formed by staggered extrusion (SE) based on the upper bound method
}

\author{
Xi Jie Zhang ${ }^{\mathrm{a}} \cdot$ Feng Li*ab $\bullet$ Ye Wang**a $\bullet$ Zi Yu Chen ${ }^{\mathrm{a}}$
}

\section{Abstract}

Staggered extrusion (SE) is a new method to solve the bottleneck of traditional curvature products, such as long manufacturing cycle, many forming processes and difficult quality control. How to quantitatively control the curvature of extruded products is the key to implement this method. Herein, the upper bound method is used to calculate and analyze the power consumption of each characteristic zone in the SE process. The theoretical model of extrusion load and curvature is established. The results show that the staggered distance $h$ has an important influence on the curvature $\kappa$. When the staggered distance $h$ increases from $8 \mathrm{~mm}$ to $24 \mathrm{~mm}$ and other conditions remain unchanged, the curvature $\kappa$ increases from 0.0546 to 0.1607 . Any combination of the staggered distance $h$ and the extrusion ratio $\lambda$ corresponds to an eccentricity ratio $\xi$. The eccentricity ratio $\xi$ decreases with the increase of the staggered distance $h$ or the extrusion ratio $\lambda$. By comparison, it can be seen that the variation trend of the theoretical predicted value and the FE modelling in the steady-state extrusion stage is consistent The experimental results are in good agreement with the curvature theory prediction model. These results provide a scientific basis for the formulation of the SE process and precisely controlling magnesium alloy curvature products.

Keywords Magnesium alloy; Staggered extrusion (SE); Upper bound method; Velocity fields; Experimental verification

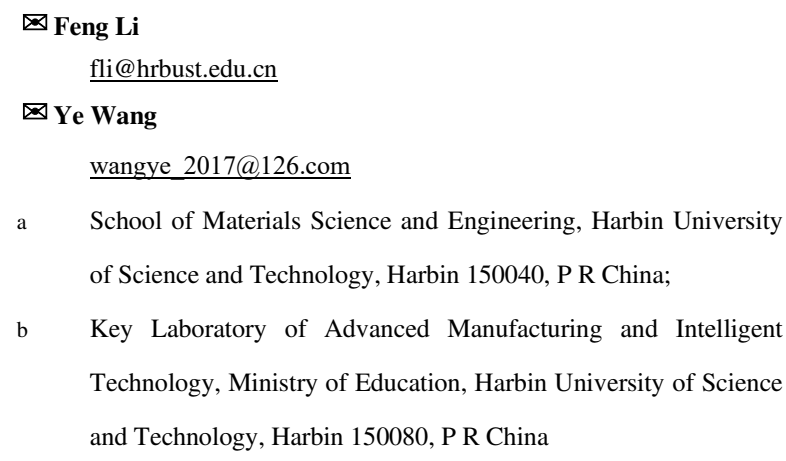

\begin{tabular}{|c|c|}
\hline \multicolumn{2}{|l|}{ Nomenclature } \\
\hline$D_{1}$ & Diameter of the billet \\
\hline$D_{2}$ & $\begin{array}{l}\text { Diameter of the extruded } \\
\text { profile }\end{array}$ \\
\hline$S_{0}$ & $\begin{array}{l}\text { Cross-sectional area of } \\
\text { the billet }\end{array}$ \\
\hline$S_{1}$ & $\begin{array}{l}\text { Cross-sectional area of } \\
\text { the extruded profile }\end{array}$ \\
\hline$S_{2}, S_{3}, S_{4}, S_{5}$ & $\begin{array}{l}\text { Cross-sectional area of } \\
\text { the related profile }\end{array}$ \\
\hline$h$ & Staggered distance \\
\hline$\Delta v, \Delta v_{1}, \Delta v_{2}, \Delta v_{3}$, and $\Delta v_{4}$ & $\begin{array}{l}\text { Amount of velocity } \\
\text { discontinuity }\end{array}$ \\
\hline$v_{1}$ & $\begin{array}{l}\text { Extrusion velocities of the } \\
\text { stem }\end{array}$ \\
\hline$v_{2}, v_{3}$ & $\begin{array}{l}\text { Velocity at the mass centre } \\
\text { of the related profile }\end{array}$ \\
\hline$v_{\mathrm{o}}$ & $\begin{array}{l}\text { Velocity at the centre of } \\
\text { the extruded profile }\end{array}$ \\
\hline$v_{\mathrm{I}}, v_{\mathrm{II}}$ & Velocity in zone I and II \\
\hline$v_{1 \mathrm{e}}, v_{2 \mathrm{e}}$ & $\begin{array}{l}\text { Maximum and minimum } \\
\text { material flow velocity } \\
\text { across the die exit }\end{array}$ \\
\hline$v_{\mathrm{z}}$ & $\begin{array}{l}\text { Material flow velocity at a } \\
\text { certain point of the die }\end{array}$ \\
\hline$F_{1}$ & Extrusion force of stem \\
\hline$\dot{W}, \dot{W}_{0}$ & $\begin{array}{l}\text { Internal and external } \\
\text { plastic dissipation power }\end{array}$ \\
\hline$\dot{W}_{i}, \dot{W}_{\Gamma}, \dot{W}_{S}$ & $\begin{array}{l}\text { Plastic dissipation power } \\
\text { due to plastic deformation, } \\
\text { velocity discontinuity } \\
\text { surface and frictional force }\end{array}$ \\
\hline$\overline{y_{i}}$ & $\begin{array}{l}\text { Coordinates of the mass } \\
\text { centre of the related profile }\end{array}$ \\
\hline$V_{i}$ & $\begin{array}{l}\text { Volume of the related } \\
\text { profile }\end{array}$ \\
\hline$R_{\mathrm{c}}$ & Bending radius of profile \\
\hline
\end{tabular}

Greek symbols 


$\begin{array}{ll}\alpha, \beta, \theta & \text { Angles in Fig. 2 } \\ l_{0} & \text { Distance between container } \\ & \text { and die } \\ l_{1} & \text { Die land length } \\ l_{2} & \text { Distance between point B } \\ & \text { and die exit } \\ l_{3} & \text { Distance between the } \\ & \text { first-touched billet part and } \\ & \text { die } \\ \lambda & \text { Extrusion ratio } \\ \xi & \text { Eccentricity ratio } \\ \tau & \text { Shear stress } \\ \mu & \text { Constant coefficient of } \\ & \text { friction } \\ \varepsilon_{\mathrm{ij}}^{*} & \text { Strain rate tensor } \\ \sigma_{\mathrm{ij}}{ }^{*} & \text { Strain tensor } \\ \kappa & \text { Curvature }\end{array}$

\section{Introduction}

Bending products are widely used in vehicle tool manufacturing, building structure design, fuel pipeline transportation and many other aspects owing to curvature profile features, convenience in use and rich functions. Generally, the traditional manufacturing mode of bending products is to first extrude the billet or profile, and then use the bending process such as stretch bending, wind bending, compressing and bending and numerical control bending [1-3]. However, the two-step method is not only a long process, but also difficult to control the shape and size accuracy. In recent years, with the further understanding and flexible application of plastic processing theory and technology, more and more attention has been paid to "one-step" direct bending product manufacturing.

Murata et al. [4] first proposed MOS bending and invented MOS pipe bending machine. MOS bending has many advantages in bending radius, precision in cross section and operability. Chatti [5] developed torque superposed spatial (TSS) bending process. It is shown that three-dimensional bending of profiles with symmetrical and asymmetrical cross-sections can be realized by TSS bending. All these bending method cannot avoid the defect of springback.

German scholar Müller et al. [6] first put forward the idea of the integration of extrusion and bending. Bending products can be obtained by using a series of guide dies. Based on this idea, some scholars putforward a new bending products forming method. Shiraishi et al. [7-9] used an inclined die to obtain pipes and bars with curvature and found that the exit height and the inclination angle of the die are important factors that affects the curvature of the products. Zhou et al. [10-13] developed differential velocity sideways extrusion (DVSE) process to directly manufacture curved profiles from conventional billet material in one operation. The results showed that punch speed ratio, extrusion ratio, die land length and die land transition corner are the factors affecting the curvature of DVSE process.

Upper bound method is a commonly used method in engineering, which can be used to estimate the force and power parameters in the forming process, analyze the deformation of metal flow and optimize the design of process parameters and dies. Based on the upper bound method, Kazanowski et al. [20] studied the influence of die structure change on extrusion results, and obtained the optimal process parameters. Zhou et al. $[14,15]$ compared the upper bound method with FE modelling and process experiment, divided the dead metal zone and plastic deformation zone in the model, and further optimized the model, which can more accurately predict the curvature of the extrusion. Altinbalik et al. [21] proposed a newly kinematical admissible velocity field to analyze different profiles of extrusion dies of clover section from round bars by upper bound analysis.

In recent years, the research team of the author has developed a series of new methods, such as extrusion through rotating container, continuous variable channel direct extrusion (CVCDE) and alternate extrusion (AE), which have solved the bottleneck problems such as low material utilization rate and difficult shape property coordination control. In addition, the SE is proposed to realize the one-step forming and manufacturing of products with curvature characteristics, which further 
expands the application scope of the existing extrusion technology. Compared with the traditional extrusion, the special structure of stem and loading mode are very different, and the extrusion flow behavior and curvature regulation are unknown. This paper focuses on this research.

\section{Theoretical analysis}

\subsection{Principle of the SE process}

The structure of the end of stem is plane in traditional forward extrusion process. When the stem is loaded downward, the billet is filled with the die cavity first, and then extruded successively. The cross-section shape of the extrusion product is determined by the die structure, and the axis is consistent with the loading direction, and the extrusion product was characterized by linearity. The end of the stem of SE process is designed as a step-like structure, which changes the stress state of each part of the billet and the extrusion flow sequence, resulting in the velocity difference at the die exit during the extrusion process, thus causing the curvature characteristics of the products. Schematic diagram of SE process is shown in Fig. 1. In this method, the influence of loading mode on extrusion flow behavior is skillfully used to control the curvature characteristics of the products, so as to realize the integration of extrusion and bending.

The preliminary results show that due to the unique step-like stem structure of the SE process, the velocity of the extruded billet is uneven and the velocity gradient is produced at the die exit, which is one of the important inducements for the bending characteristics of the products. It is also found that the extrusion ratio $\lambda$ and staggered distance $h$ are two important factors affecting the curvature of extruded products, and both of them are proportional to the curvature of products [16, 17]. In addition, the SE process has a certain effect on grain refinement, and the grain refinement is more significant with the increase of the extrusion ratio $\lambda$ or the staggered distance $h$ [18].

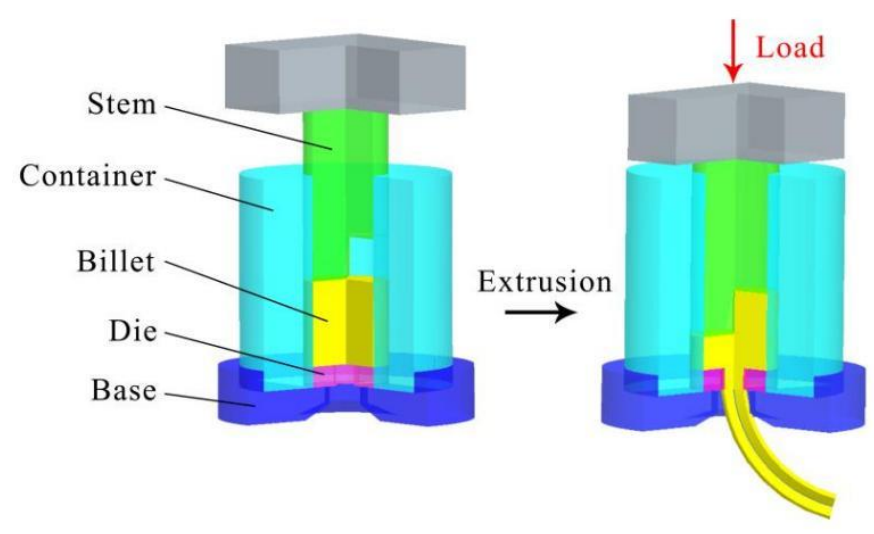

Fig. 1 The schematic diagram of the SE process

\subsection{Upper bound model}

From the above analysis, it can be seen that the special stem structure of SE causes significant difference in load variation, and the adjustment of the curvature of the extrusion product is particularly important. In this paper, the upper bound method is used to establish the corresponding theoretical model to analyze the extrusion load and curvature change in the forming process. Fig. 2 shows the two dimensional model of the SE process. As can be seen in Fig. 2a) and Fig. 2b) that the metal around the bottom corner of the container is affected by the two-way friction between container and die in the process of extrusion, so the metal flow in this part is relatively slow or even almost still, which is called 


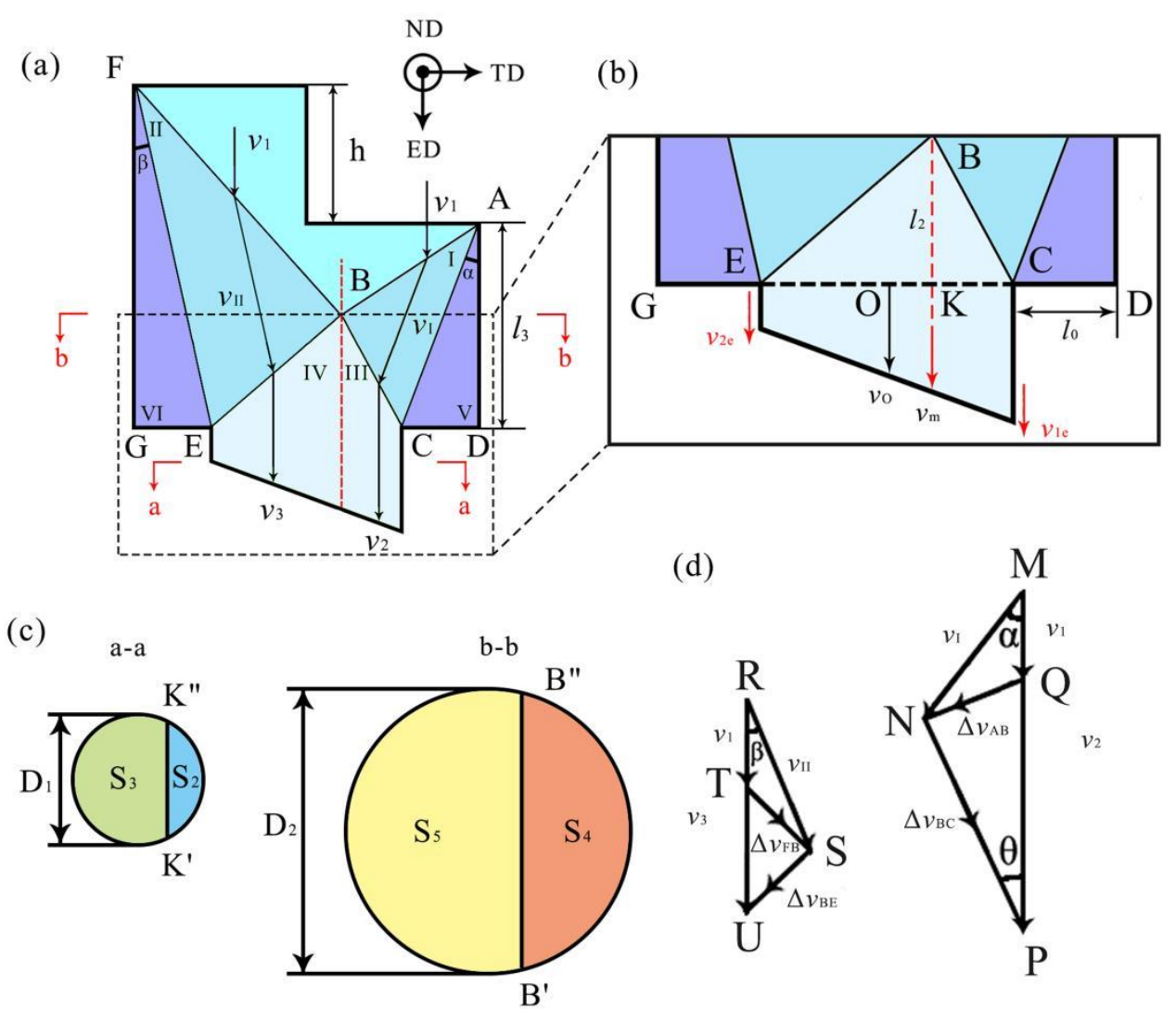

Fig. 2 The two dimensional model of the SE process: a) zone division of deformation b) model details in zones III and V c) the projection of BB" into the related profile of the die and billet d) the related hodograph the dead metal zone (DMZ). Due to the special structure of the stepped structure designed at the end of the stem, the angle between the plastic deformation zone (PDZ) and container changes. The height of the dead metal zone is limited by steps, and it is fixed as $l_{3}$ and $l_{3}+h$ in the ND direction. When backward extrusion is completed, in ND directions, DMZ reaches the maximum value, namely zone $\mathrm{V}$ and $\mathrm{VI}$ reaches maximum value. The angle of the DMZ causes the metal flow at the die exit not to be distributed symmetrically along the central axis, as is the case with normal positive extrusion, but to shift to the side with a larger angle of the DMZ, which leads to the bending characteristic of the products. The offset of the central axis divided the diameter length of die exit into two sections: $\xi D_{2}$ and $(1-\xi) D_{2}$. Here the variable eccentricity ratio $\xi=\mathrm{g}(h, \lambda)$ were fixed in the same extrusion ratio $\lambda$ and the staggered distance $h$. When the staggered distance $h=0$, that is, during the normal normal extrusion, the eccentricity ratio $\xi=0.5$, point $\mathrm{B}$ is on the extrusion axis. With the increase of the staggered distance $h$, the eccentricity ratio $\xi$ decreased and point $\mathrm{B}$ began to move toward the first-touched billet part. Here the extrusion ratio $\lambda$ is defined by

$$
\lambda=\frac{S_{0}}{S_{2}+S_{3}}=\frac{S_{0}}{S_{1}}=\frac{D_{1}^{2}}{D_{2}^{2}}
$$

Zones I $\sim$ IV are the plastic deformation zone (PDZ), and zones V and VI are the dead metal zone (DMZ). PDZ is divided into four zones by velocity discontinuity surfaces $A B, B C, B E$ and $B F$. The billet moves rigidly towards the velocity discontinuity surfaces $\mathrm{AB}$ and $\mathrm{BF}$ at the speed of $v_{1}$ until the direction and size of the billet change to $v_{\mathrm{I}}$ and $v_{\mathrm{II}}$ after being subjected to the velocity discontinuities $\Delta v_{\mathrm{AB}}$ and $\Delta v_{\mathrm{BF}}$. The maximum angles of $v_{\mathrm{I}}$ and $v_{\mathrm{II}}$ are $\alpha$ and $\beta$ in zones I and II respectively. Subsequently, $v_{\mathrm{I}}$ and $v_{\text {II }}$ are subjected to velocity discontinuities $\Delta v_{\mathrm{BC}}$ and 
$\Delta v_{\mathrm{BE}}$, and are forced to enter zones III and IV at the assumed velocities $v_{2}$ and $v_{3}$ in the extrusion direction, where the velocity components are shown in Fig. 2d). Where $v_{2}$ and $v_{3}$ are the average velocities in zones III and IV and are also velocities at the mass centre. Since there is no velocity discontinuity in zones III and IV, a velocity gradient is generated at the die exit. $v_{1 \mathrm{e}}$ is the maximum velocity of the die exit, $v_{2 \mathrm{e}}$ is the minimum velocity of the die exit, and $v_{\mathrm{m}}$ is the velocity at the boundary between zones III and IV.

Li et al. [19] pointed out that the die land length is an important factor affecting the shape of the extrusion products, and the short die land length makes the bending trend of the extrusion products larger. Therefore, the die land length $l_{1}$ at the extrusion die exit should not be too long, as shown in Fig. 2b). According to the principle of volume invariance, the flow velocities $v_{2}$ and $v_{3}$ at the mass centers of zones III and IV are as follows:

$$
\begin{aligned}
& v_{2}=\frac{S_{4}}{S_{2}} v_{1} \\
& v_{3}=\frac{S_{5}}{S_{3}} v_{1}
\end{aligned}
$$

Where, the cross-sectional area S0 of the billet and the cross-sectional area $S_{1}$ of the die exit are Eq. (4) and Eq. (5). Fig. 2c) is the area $S_{2}, S_{3}, S_{4}$ and $S_{5}$ divided by the cross-sectional area $S_{0}$ of the billet and the cross-sectional area $S_{1}$ of the die exit by the offset extrusion shaft [22]. The calculation method is shown in Eq. (4) - Eq. (7).

$$
\begin{gathered}
S_{0}=\frac{\pi D_{1}^{2}}{4} \\
S_{1}=\frac{\pi D_{2}^{2}}{4} \\
S_{2}=\frac{D_{2}^{2}}{4} \arccos (1-2 \xi)-\left(\frac{1}{2}-\xi\right) \sqrt{\xi-\xi^{2}} D_{2}^{2} \\
S_{3}=\frac{D_{2}^{2}}{4}[\pi-\arccos (1-2 \xi)]+\left(\frac{1}{2}-\xi\right) \sqrt{\xi-\xi^{2}} D_{2}^{2} \\
S_{4}=\frac{D_{1}^{2}}{4} \arccos \left(\frac{D_{1}-2 \xi D_{2}-2 l_{0}}{D_{1}}\right) \\
-\left(\frac{D_{1}}{2}-\xi D_{2}-l_{0}\right) \sqrt{\left(l_{0}+\xi D_{2}\right)\left(D_{1}-\xi D_{2}-l_{0}\right)}
\end{gathered}
$$

$$
\begin{aligned}
& S_{5}=\frac{D_{1}^{2}}{4}\left[\pi-\arccos \left(\frac{D_{1}-2 \xi D_{2}-2 l_{0}}{D_{1}}\right)\right] \\
& +\left(\frac{D_{1}}{2}-\xi D_{2}-l_{0}\right) \sqrt{\left(l_{0}+\xi D_{2}\right)\left(D_{1}-\xi D_{2}-l_{0}\right)}
\end{aligned}
$$

The power consumption $\dot{W}$ due to plastic deformation of is equal to the external plastic dissipation power $\dot{W}_{0}$, as expressed in Eq. (10).

$$
\dot{W}=\dot{W}_{0}
$$

The power consumption is expressed as sum, which can be obtained by

$$
\dot{W}=\dot{W}_{i}+\dot{W}_{\Gamma}+\dot{W}_{S}
$$

where $\dot{W}_{i}$ is the plastic dissipation power due to plastic deformation, $\dot{W}_{\Gamma}$ is the plastic dissipation power due to velocity discontinuity surface and $\dot{W}_{S}$ is the plastic dissipation power due to frictional force.

In order to calculate the area of discontinuities more accurately, The three dimensional model of velocity discontinuity of the SE process is designed. The corresponding velocity discontinuities are shown in Fig. 3.

The first term on the right side of Eq. (11) is as follows:

$$
\dot{W}_{i}=\int_{\mathrm{V}} \sigma_{\mathrm{ij}}^{*} \varepsilon_{\mathrm{ij}}^{*} d V=\frac{2}{\sqrt{3}} \sigma_{\mathrm{s}} \int_{\mathrm{V}} \sqrt{\frac{1}{2} \dot{\varepsilon}_{\mathrm{ij}} \dot{W}_{i j}} d V
$$

Wherein, $\dot{W}_{i 1}$ and $\dot{W}_{i 2}$ are the power consumption of PDZ consumed by $v_{1}$ through the plastic deformation zone, which can be given by

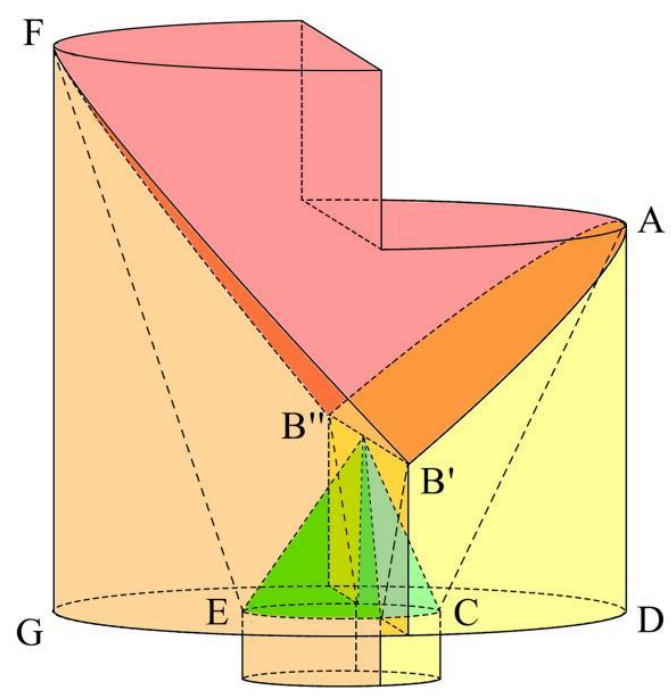

Fig. 3 The three dimensional model of velocity discontinuity of the SE process 


$$
\begin{aligned}
& \dot{W}_{i_{I}}=\int_{V} \sigma_{\mathrm{ij}}^{*} \varepsilon_{\mathrm{ij}}^{*} d V=\frac{4}{\sqrt{3}} \sigma_{\mathrm{s}} v_{1}\left(\xi D_{2}+l_{0}\right)^{2} \sin \alpha \\
& \times \int_{\arctan \frac{\pi}{2} \frac{\pi}{2}}^{\frac{\pi}{2}+\frac{\sum_{2}}{L_{2}} \frac{l_{3}-l_{2}}{\sum_{2}+l_{0}}} \frac{\sqrt{\operatorname{ctg}^{2} \varphi+4}}{\sin ^{2} \varphi \sin (\alpha+\varphi)} d \varphi \\
& \dot{W}_{i I I}=\int_{V} \sigma_{i j}^{*} \varepsilon_{i j}^{*} d V=\frac{4}{\sqrt{3}} \sigma_{s} v_{1}\left[(1-\xi) D_{2}+l_{0}\right]^{2}
\end{aligned}
$$

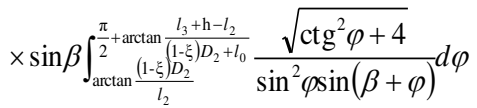

The second term $\dot{W}_{\Gamma}$ on the right of Eq. (11) is as follows:

$$
\begin{aligned}
\dot{W}_{\Gamma} & =\int_{\Gamma} \tau|\Delta v| d \Gamma \\
& =\dot{W}_{S_{A B}}+\dot{W}_{S_{B F}}+\dot{W}_{S_{B C}}+\dot{W}_{S_{B E}}+\dot{W}_{S_{A C}}+\dot{W}_{S_{E F}}
\end{aligned}
$$

where $\dot{W}_{\mathrm{SAB}}$ and $\dot{W}_{\mathrm{SBF}}$ are the power consumption consumed by $v_{1}$ in the first stage through the velocity discontinuity surface SAB'B" and SFB'B", as shown in Eq. (15) and Eq. (16).

$$
\begin{aligned}
\dot{W}_{S_{A B}} & =\int_{\Gamma_{1}} \tau\left|\Delta v_{1}\right| d \Gamma_{1} \\
& =\frac{B v_{2} \xi\left[\left(\xi D_{2}+l_{0}\right)^{2}+\left(l_{3}-l_{2}\right)^{2}\right]}{\left(\xi D_{2}+l_{0}\right)\left(l_{3} \xi D_{2}+l_{0} l_{2}\right)} \\
\dot{W S}_{S_{B F}} & =\int_{\Gamma_{2}} \tau\left|\Delta v_{2}\right| d \Gamma_{2} \\
= & \frac{B v_{3}(1-\xi)\left\{\left[(1-\xi) D_{2}+l_{0}\right]^{2}+\left(l_{3}+h-l_{2}\right)^{2}\right\}}{\left.\left[(1-\xi) D_{2}+l_{0}\right]\left(l_{3}+h\right)(1-\xi) D_{2}+l_{0} l_{2}\right]}
\end{aligned}
$$

where

$$
B=\frac{1}{2} \tau \pi l_{0} D_{2} \sqrt{\left(\xi D_{2}+l_{0}\right)\left(D_{1}-\xi D_{2}-l_{0}\right)}
$$

After passing through the velocity discontinuity SAB'B" and SFB'B", $v_{1}$ becomes velocity $v_{\mathrm{I}}$ and $v_{\mathrm{II}}$, $\dot{W}_{\mathrm{SBC}}$ and $\dot{W}_{\mathrm{SBE}}$ the power consumption of $v_{\mathrm{I}}$ and $v_{\mathrm{II}}$ passing through the velocity discontinuity SBEC, which can be written as

$$
\begin{aligned}
\dot{W}_{S_{B C}} & \int_{\Gamma_{3}} \tau\left|\Delta v_{3}\right| d \Gamma_{3}=4 \tau v_{2} l_{0} \sqrt{l_{2}^{2}+\left(\xi D_{2}\right)^{2}} \\
& \times \int_{l_{2}}^{l_{3}} \frac{1}{\xi D_{2} x+l_{0} l_{2}} d x \int_{\xi D_{2}}^{D_{2} \sqrt{\xi \xi^{2}}} \sqrt{y^{2}+l_{2}^{2}} d y \\
\dot{W}_{S_{B E}} & =\int_{\Gamma_{4}} \tau\left|\Delta v_{4}\right| d \Gamma_{4}=4 \tau v_{3} l_{0} \sqrt{l_{2}^{2}+\left[(1-\xi) D_{2}\right]^{2}} \\
& \times \int_{l_{2}}^{l_{3}+h} \frac{1}{(1-\xi) D_{2} x+l_{0} l_{2}} \int_{D_{2} \sqrt{\xi-\xi \xi^{2}}}^{(1-\xi) D_{2}} \sqrt{y^{2}+l_{2}^{2}} d y
\end{aligned}
$$

$\dot{W}_{\text {SAC }}$ and $\dot{W}_{\text {SEF }}$ are the power consumption at the boundary of PDZ and DMZ, which can be defined as

$$
\begin{aligned}
& \dot{W}_{S_{A C}}=\int_{\Gamma_{5}} \tau\left|\Delta v_{5}\right| d \Gamma_{5} \\
& =4 \tau v_{2} \xi D_{2} \int_{l_{2}}^{l_{3}} \frac{\sqrt{x^{2}+l_{0}^{2}}}{\xi D_{2} x+l_{0} l_{2}} d x \int_{l_{2}}^{l_{3}} \sqrt{y^{2}+l_{0}^{2}} d y
\end{aligned}
$$

$$
\begin{aligned}
& \dot{\mathrm{W}}_{\mathrm{S}_{\mathrm{FF}}}=\int_{\Gamma_{6}} \tau\left|\Delta v_{6}\right| \mathrm{d} \Gamma_{6} \\
& =4 \tau v_{3}(1-\xi) D_{2} \int_{l_{2}}^{l_{3}+\mathrm{h}} \frac{\sqrt{x^{2}+l_{0}^{2}}}{(1-\xi) D_{2} x+l_{0} l_{2}} d x \int_{l_{2}}^{l_{3}+\mathrm{h}} \sqrt{y^{2}+l_{0}^{2}} d y
\end{aligned}
$$

The third term $\dot{W}_{S}$ on the right of Eq. (11) is as follows:

$$
\begin{gathered}
\dot{W}_{s}=\int_{S_{f}} \mu \tau \Delta v d S_{f}=\dot{W}_{S_{f_{1}}}+\dot{W}_{S_{f_{2}}} \\
\dot{W}_{S_{f_{1}}}=\int_{S_{f_{1}}} \mu \tau \Delta v d S_{f_{1}} \\
=\mu \tau v_{1} D_{1}\left[\left(l_{3}-l_{2}\right) \pi+\frac{h}{2} \arccos \left(\frac{D_{1}-2 l_{0}-2 \xi D_{2}}{D_{1}}\right)\right] \\
\dot{W}_{S_{f_{2}}}=\int_{S_{f_{2}}} \mu \tau \Delta v d S_{f_{2}} \\
=\mu \tau l_{1} D_{2}\left[\pi v_{3}+\left(v_{2}-v_{3}\right) \arccos (1-2 \xi)\right]
\end{gathered}
$$

where $\dot{W}_{S f 1}$ is the friction power consumption between the billet entering PDZ and the container, and $\dot{W}_{S f 2}$ is the friction power consumption of the billet at the die exit.

To sum up, the internal plastic dissipation power $\dot{W}$ during extrusion is shown in Eq. (26).

$$
\begin{aligned}
\dot{W}= & \dot{W}_{i}+\dot{W}_{\Gamma}+\dot{W}_{S} \\
= & \dot{W}_{i}+\dot{W}_{i I I}+\dot{W}_{S_{A B}}+\dot{W}_{S_{B F}}+\dot{W}_{S_{B C}} \\
& +\dot{W}_{S_{B E}}+\dot{W}_{S_{A C}}+\dot{W}_{S_{E F}}+\dot{W}_{S_{f_{1}}}+\dot{W}_{S_{f_{2}}}
\end{aligned}
$$

In the SE process, owing to the fact that the die is fixed, the extrusion ratio $\lambda$, staggered distance $h$, diameter of the billet $D_{1}$, diameter of the extruded profile $D_{2}$, distance between container and die $l_{0}$ and die land length $l_{1}$ are all constant. Altinbalik et al. [21] put forward a method to measure the distance between point $\mathrm{B}$ and die exit, that is, to print grid on the cross-sectional area of billet, determine the range of deformation increase by observing the change of mesh shape after extrusion forming, and determine the distance $l_{2}$ between point $\mathrm{B}$ and die exit. Therefore, the distance $l_{2}$ between point $\mathrm{B}$ and die exit is also determined. The external parameters such as extrusion speed $v_{1}$, shear stress $\tau$ and friction coefficient $\mu$ are also fixed, and only the distance between the first-touched billet part and die $l_{3}$ caused by reduction is changed.

The total power is a function of eccentricity ratio $\xi$. When the internal plastic dissipation power reaches 
the minimum, the value of eccentricity ratio $\xi$ can be obtained

$$
\frac{\partial \dot{W}}{\partial \xi}=0
$$

Eccentricity ratio $\xi$ is determined by the extrusion ratio $\lambda$ and staggered distance $h$. Fig. 4a) shows the relationship between eccentricity ratio $\xi$ and extrusion ratio $\lambda$ and staggered distance $h$. According to Eq. (27), eccentricity ratio $\xi$ at the maximum load under different staggered distance $h$ and extrusion ratio $\lambda$ is obtained, as shown in Table 1. It can be seen that when the extrusion ratio $\lambda$ is 11.11 , the eccentricity ratio $\xi$ with the staggered distance $h$ of $8 \mathrm{~mm}$ is 0.4619 , and the eccentricity ratio $\xi$ decreases to 0.3233 as the staggered distance $h$ increases to $24 \mathrm{~mm}$. In the longitudinal direction, the extrusion ratio $\lambda$ increases from 11.11 to 44.44 , and the eccentricity ratio $\xi$ decreases from 0.4619 to 0.4527 . Therefore, the eccentricity ratio $\xi$ decreases with the increase of staggered distance $h$ or extrusion ratio $\lambda$.

Table 1 The value of eccentricity ratio $\xi$ at the maximum load under different staggered distance $h$ and extrusion ratio $\lambda$

\begin{tabular}{ccll}
\hline$\lambda$ & $\mathrm{h}=8 \mathrm{~mm}$ & $\mathrm{~h}=16 \mathrm{~mm}$ & $\mathrm{~h}=24 \mathrm{~mm}$ \\
\hline 11.11 & 0.4619 & 0.3880 & 0.3233 \\
19.75 & 0.4550 & 0.3788 & 0.3118 \\
44.44 & 0.4527 & 0.3718 & 0.3048 \\
\hline
\end{tabular}

The power calculated by the upper bound method is greater than or equal to the power consumed by the billet deformation in the actual extrusion process. Since the extrusion speed $v_{1}$ can be determined, the best upper limit value $F_{1}$ can be determined when the eccentricity ratio $\xi$ is the minimum. The three dimensional load curve under different extrusion ratio $\lambda$ and staggered distance $h$ is shown in Fig. 4b).

$$
F_{1}=\frac{\dot{W}_{\min }}{v_{1}}=\frac{\dot{W}}{v_{1}}
$$

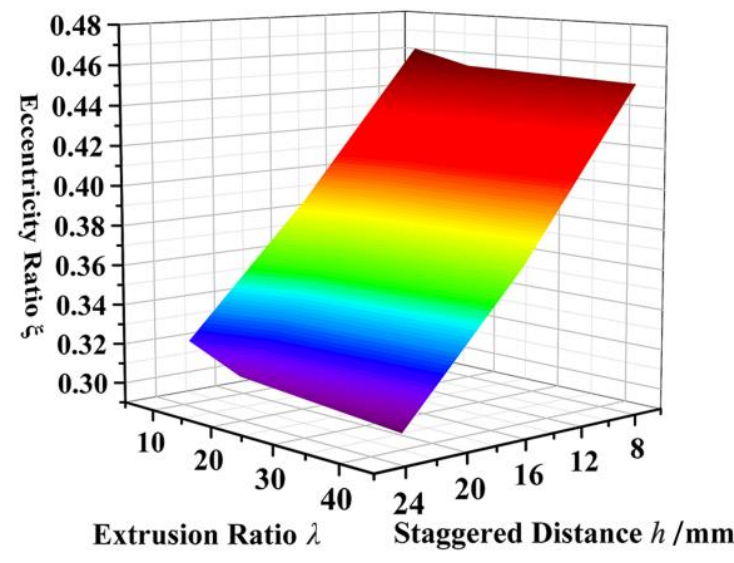

(a)

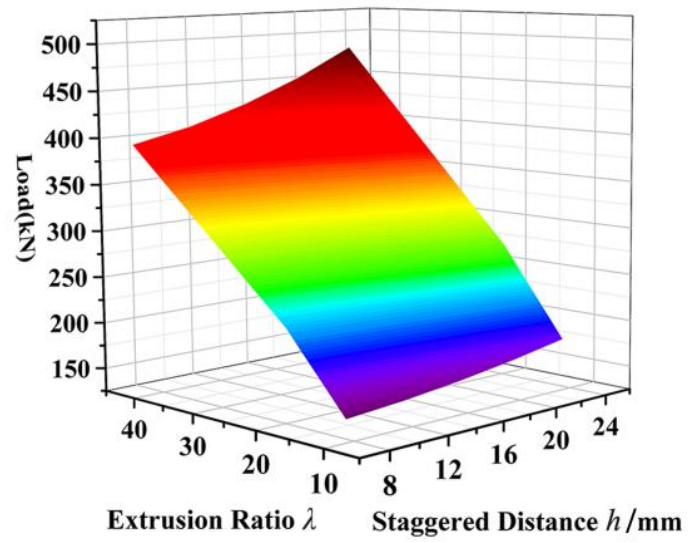

(b)

Fig. 4 The relationship between the parameters: a) the relationship among eccentricity ratio $\xi$, staggered distance $h$ and extrusion ratio $\lambda \mathrm{b}$ ) relationship between load and extrusion ratio $\lambda$ and staggered distance $h$

\subsection{Curvature calculation}

According to Fig. 2a), due to the existence of eccentricity ratio $\xi$, the die exit is projected into two parts, $S_{2}$ and $S_{3}$, and the velocities of the mass centre are $v_{2}$ and $v_{3}$, respectively. It can be seen from Eq. (2) - Eq. (9) that eccentricity ratio $\xi$ affects the velocities of the mass centre $v_{2}$ and $v_{3}$. Since the whole model is symmetrical about the cross section in Fig. 2a), the mass centers $\mathrm{O}_{2}$ and $\mathrm{O}_{3}$ are equal in the $\mathrm{x}$-axis direction. Only $\bar{y}_{2}$ and $\bar{y}_{3}$ need to be calculated. $\bar{y}_{\mathrm{i}}$ is used to combine $\bar{y}_{2}$ and $\bar{y}_{3}$, and the calculation formula is as follows:

$$
\begin{aligned}
& \bar{y}_{i}=\frac{\int_{V} y d V_{i}}{V_{i}}=\frac{\int_{S_{i}} y v_{z} d S_{i}}{S_{i} v_{i}} \\
& =\frac{\left(v_{i}-v_{0}\right)}{S_{i} v_{i} \bar{y}_{i}}\left[(-1)^{i+1} L+M\right]+\frac{(-1)^{i} N}{S_{i} v_{i}}
\end{aligned}
$$

where 


$$
\begin{gathered}
L=\frac{D_{2}^{4}}{64}\left[2(1-2 \xi) \sqrt{\xi-\xi^{2}}\left(8 \xi^{2}-8 \xi+1\right)+\arcsin (1-2 \xi)\right] \\
M=\frac{D_{2}^{4} \pi}{128} \\
N=\frac{2}{3} v_{0} D_{2}^{3}\left(\xi-\xi^{2}\right)^{\frac{3}{2}} \\
\bar{y}_{i}=\frac{(-1)^{i} N}{2 S_{i} v_{i}} \\
+(-1)^{i} \sqrt{\left(\frac{N}{2 S_{i} v_{i}}\right)^{2}+\frac{\left(v_{i}-v_{0}\right)}{S_{i} v_{i}}\left[(-1)^{i+1} L+M\right]} \\
v_{z}=\frac{v_{i}-v_{0}}{y_{i}} y+v_{0}
\end{gathered}
$$

Eq. (29) can be simplified as Eq. (33). In Eq. (29) - Eq. (36), $i$ is taken as 2 or 3. The maximum and minimum material flow velocity across the die exit v1e and v2e can be obtained by introducing $0.5 D_{2}$ and $-0.5 D_{2}$ of $y$ into Eq. (34).

For particles $\mathrm{O}_{2}$ and $\mathrm{O}_{3}$, it is assumed that $\Delta d_{2}$ and $\Delta d_{3}$ are moved in a very short time $\Delta t$. because $v_{2}>v_{3}, \Delta d_{2}>\Delta d_{3}$, that is, the extrusion products bending characteristics, and its bending angle is $\Delta \theta$. According to the displacement and arc length formula:

$$
\begin{gathered}
\Delta d_{i}=v_{i} \Delta t \\
\Delta d_{i}=\Delta \theta\left(R_{c}+\bar{y}_{i}\right)
\end{gathered}
$$

By introducing Eq. (35) into Eq. (36), the bending radius of profile Rc and curvature $\kappa$ can be obtained

$$
\begin{gathered}
R_{c}=\frac{\bar{y}_{2} v_{2}-\bar{y}_{3} v_{3}}{v_{2}-v_{3}} \\
=\frac{N S_{1}+\sum_{i=2}^{3} S_{i} \sqrt{N^{2}+4\left(v_{i}-v_{0}\right)(M-L) v_{i} S_{i}}}{2\left(v_{2}-v_{3}\right) S_{2} S_{3}} \\
\kappa=\frac{1}{R_{c}}
\end{gathered}
$$

\section{Material and methods}

\subsection{Research program}

The experimental material is commercial as cast AZ31 magnesium alloy bar. The sample of $\Phi 40 \mathrm{~mm} \times 40 \mathrm{~mm}$ is made by turning lathe. There are a lot of dendrites and coarse eutectic phases in as cast alloy. In order to eliminate the composition segregation, improve the inhomogeneity of the structure and the plastic deformation ability, the billet is homogenized. The billet was homogenized at $673 \mathrm{~K}$ for $12 \mathrm{~h}$ and then air cooled. AZ31 magnesium alloy yield strength is $140 \mathrm{MPa}$ and Poisson's ratio is 0.35 . The billet and the contact part of the die were coated with oil-based graphite and assembled. The die was put into the resistance furnace for heating to the experimental temperature and holding for a period of time. It was quickly moved to the workbench for extrusion forming. Then the extruded products were water quenched to preserve the microstructure of hot deformation for subsequent observation. The experimental scheme is shown in Table 2. In the experiment, the forming temperature is $625 \mathrm{k}$, the extrusion speed is $1 \mathrm{~mm} / \mathrm{s}$, staggered distance $h$ is $8 \mathrm{~mm}, 16 \mathrm{~mm}$ and $24 \mathrm{~mm}$, and the extrusion ratio $\lambda$ is $11.11,19.75$ and 44.44 respectively.

Table.2 Experimental scheme parameters

\begin{tabular}{ccccc}
\hline Parameter & $\begin{array}{c}\text { Extrusion } \\
\text { Temperature, } \mathrm{T} \\
(\mathrm{K})\end{array}$ & $\begin{array}{c}\text { Extrusion } \\
\text { Speed, } v_{1} \\
(\mathrm{~mm} / \mathrm{s})\end{array}$ & $\begin{array}{c}\text { Staggered } \\
\text { Distance, } h \\
(\mathrm{~mm})\end{array}$ & $\begin{array}{c}\text { Extrusion } \\
\text { Ratio, } \lambda \\
\left(\mathrm{mm}^{2} / \mathrm{mm}^{2}\right)\end{array}$ \\
\hline \multirow{2}{*}{ Content } & & & 8 & 11.11 \\
& 625 & 1 & 16 & 19.75 \\
\end{tabular}

In order to determine the distance $l_{2}$ between point $\mathrm{B}$ and die exit, the billet is prefabricated into two half symmetrical structures, and a uniform mesh with the size of $2 \mathrm{~mm} \times 2 \mathrm{~mm}$ is carved on the cross section by wire cutting. The size of $l_{2}$ is determined by measuring the deformation zone and radial metal flow range. The extrusion process was modeled using the finite element software Deform-3D. In the simulation parameters, the extrusion temperature is $625 \mathrm{~K}$. The extrusion speed 
is $1 \mathrm{~mm} / \mathrm{s}$. The friction coefficient is 0.3 . The heat transfer coefficient between tooling and billet is 11 $\mathrm{N} /{ }^{\circ} \mathrm{C} \mathrm{s} \mathrm{mm}{ }^{2}$. The mesh interference depth is 0.7 . The FE modelling, theoretical and experimental results are compared and analyzed.

\subsection{Curvature measurement}

The curved plane of extruded product axis is two-dimensional because point $\mathrm{B}$ is only offset in TD direction. Fig. 5 shows the bending curvature calculation method. Connect the beginning and end of the bending part. Divide the straight line into 10 equal parts. Make a vertical line corresponding to 11 points on the bending part. Connect two adjacent points, and make vertical bisectors on the 10 segments of the line, intersecting at the inner side of the curve. Measure the distance from the point to the bending part, and the length is the bending radius of profile Rc. Take the reciprocal and the value is the curvature $\kappa$. For the real products curvature measurement, the curved shape can be printed on the paper.

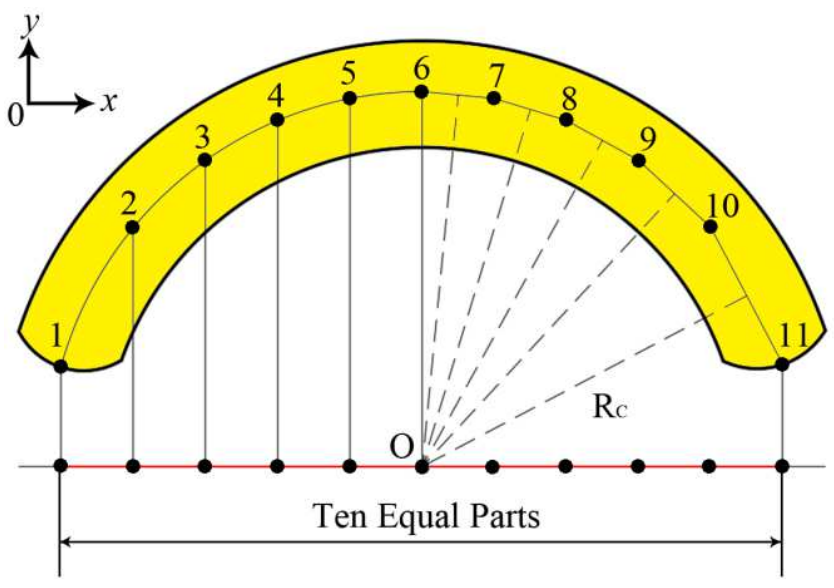

Fig. 5 Point selection and curvature calculation

\section{Results and Discussion}

\subsection{Extrusion load}

Due to the fact that the end of stem is designed as a special step structure, it not only has an important impact on the metal flow behavior, but also has a more distinct change characteristics of displacement-load curve compared with traditional extrusion. Wang et al. [17] preliminary analyzed the displacement-load variation law of SE with cone angle of die. In this study, the cone angle of the die is $90^{\circ}$, that is, the SE of the flat die. Therefore, during the backward extrusion process, there is no billet filling the core die cone angle cavity, and the displacement-load curve changes as shown in Fig. 6. From the change process, it can be divided into four stages: upsetting, extrusion of billet from die, filling completely and steady-state extrusion.
In the first stage, when the stem end contacts the billet, the billet is compressed and deformed to fill

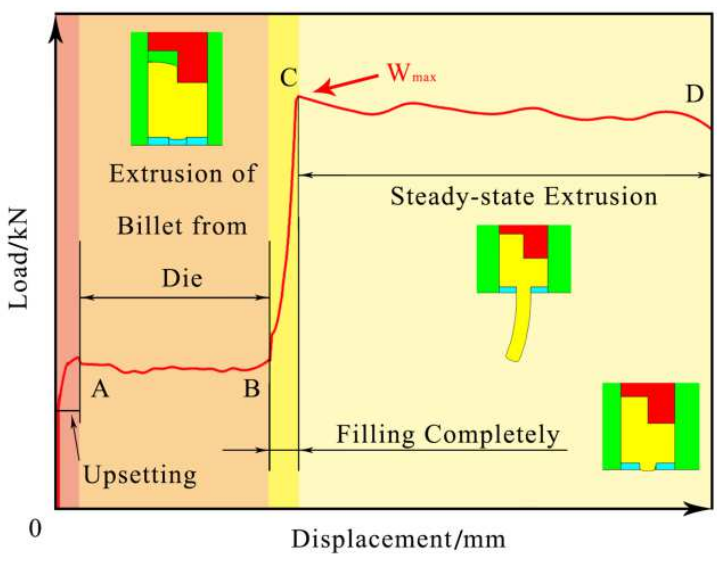

Fig. 6 Displacement-load relationship in SE the cavity gap in the container. It is in an upward trend until it reaches point $\mathrm{A}$. When the stem continues to downward loading, the billet begins to be backward extruded, and some materials begin to flow to the die exit, so the load value decreases, that 
is, from A to B. When the billet completely fills the gap at the end step of the stem, and under the continuous loading, all the billet in the container reaching the maximum value $W_{\max }$ in the extrusion process. Then it enters the steady-state extrusion stage. With the continuous extrusion of the billet, the friction between the billet and the container decreases, and the load value required by the stem to overcome the friction force also gradually decreases, which is consistent with the regular extrusion load variation law.

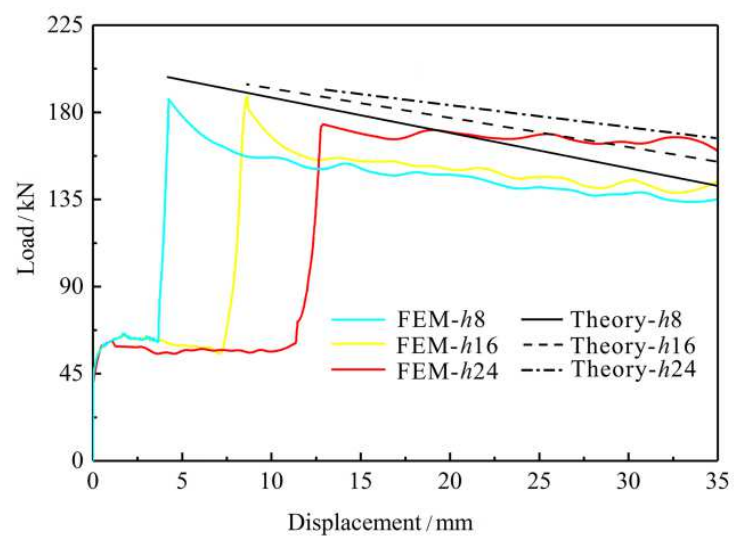

Fig. 7 the comparison of FE modelling and theory of load in $\lambda=11.11, h=8 \mathrm{~mm}, 16 \mathrm{~mm}$ and $24 \mathrm{~mm}$ respectively

The theoretical model of the required extrusion load is derived. For verification, the displacement-load variation of the staggered distance $h$ of $8 \mathrm{~mm}, 16 \mathrm{~mm}$ and $24 \mathrm{~mm}$ under the extrusion ratio $\lambda$ of 11.11 is compared as an example, as shown in Fig. 7.

At first, because the billet is in the backward extrusion stage, the extrusion load does not reach the maximum value. With the increase of reduction, the billet backward extrusion is complete and reaches the peak maximum value. The size of the friction surface between the billet and the die is different. Under the same displacement, the smaller the staggered distance $h$, the smaller the friction surface between the billet and the die, and the smaller the load. When the extrusion force reaches the maximum value, the theoretical model is basically the same as the simulation trend. Since the upper bound method is the upper limit of the data obtained by the upper bound method, the value is flows towards the die exit and is extruded in sequence. In this process, the displacement load value increases significantly, rising to point $C$, greater than those obtained by FE modelling, which is a normal phenomenon.

\subsection{Curvature}

From the above analysis, it can be seen that there is a maximum die velocity $v_{\text {le }}$ and a minimum die velocity $v_{2 \mathrm{e}}$ on the side of the maximum angle $\alpha$ and the minimum angle $\beta$ of DMZ respectively, and the velocity of the zones III and IV is continuous, which makes the velocity gradient in the two zones. Due to the gradient distribution of extrusion velocity on the die plane, the curvature characteristics of extrusion products are produced. Fig. 8 shows the theoretical and simulation comparison of the maximum and minimum flow velocity at the die mouth with the die hole diameter $D_{2}$ of $6 \mathrm{~mm}, 9 \mathrm{~mm}$ and $12 \mathrm{~mm}$ under different staggered distance $h$, that is, the extrusion ratio $\lambda$ is $11.11,19.45$ and 44.44 , respectively. It can be seen that with the increase of extrusion ratio $\lambda$, the die flow rate values are increasing. In the case of the same extrusion ratio $\lambda$, the difference between the maximum flow rate and the minimum flow rate increases with the increase of the staggered distance $h$. The same staggered distance $h$ makes the difference between the velocity difference and the extrusion ratio $\lambda$ changes in direct proportion.

Fig. 9 shows the relationship between staggered distance $h$, diameter of the extruded profile $D_{2}$ and curvature $\kappa$. It can be seen from Eq. (1) that the larger the diameter of the extruded profile $D_{2}$ is, the smaller the extrusion ratio $\lambda$ is under the same diameter of the billet. It can be seen from Fig. 9a) that under the same extrusion ratio $\lambda$, with the increase of staggered distance $h$, the value of curvature $\kappa$ increases. The small staggered distance $h$ makes the curvature $\kappa$ increased more obviously, while the large staggered distance $h$ makes the curvature $\kappa$ increases slowly. The overall curvature $\kappa$ increases. According to the model analysis, 


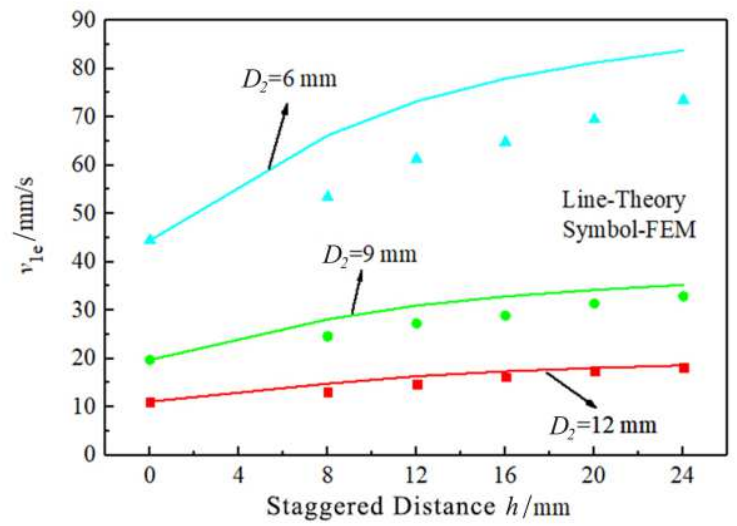

(a)

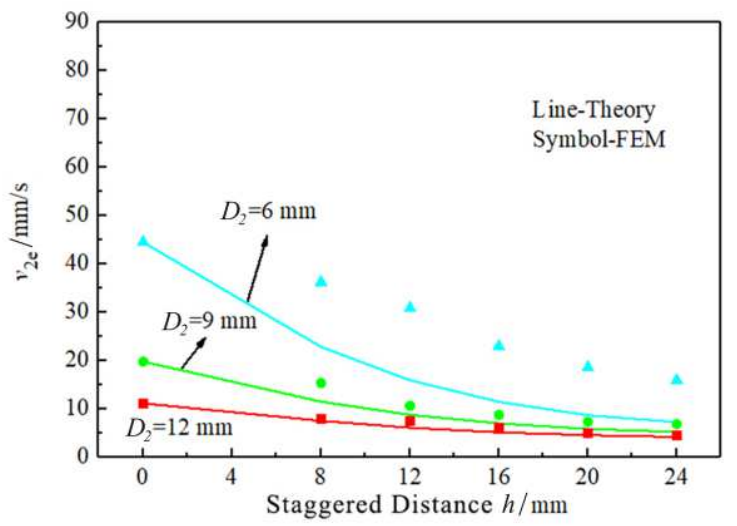

(b)

Fig. 8 Comparison of velocity extremes at die exit: a) maximum velocity b) minimum velocity

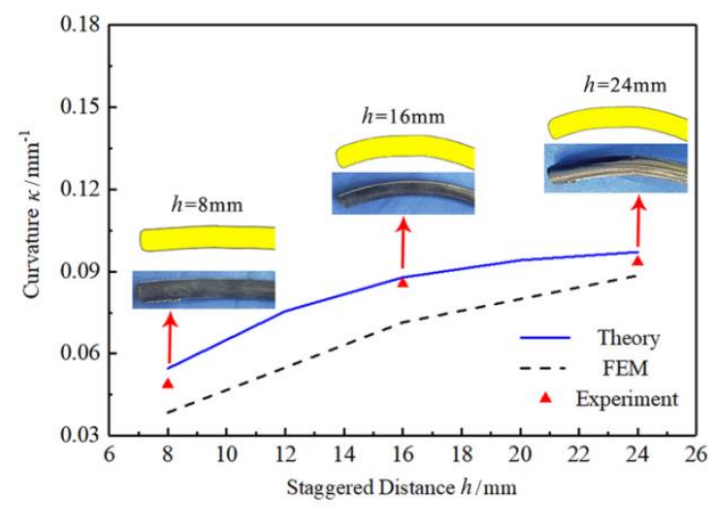

(a)

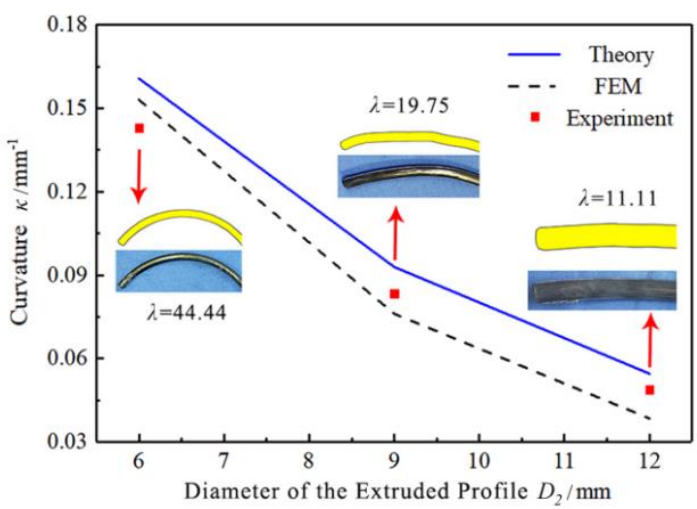

(b)

Fig.9 The relationship between staggered distance $h$, diameter of the extruded profile $D_{2}$ and curvature $\kappa$ : a) staggered distance $h$ b)diameter of the extruded profile $D_{2}$

eccentricity ratio $\xi$ is the main factor affecting the curvature $\kappa$ of the product when the staggered distance $h$ is small. The large staggered distance $h$ causes the friction surface of the billet increased. Although the eccentricity ratio $\xi$ is large, the initial extrusion speed $v_{1}$ is greatly consumed after passing through the velocity discontinuity surface. Here staggered distance $h$ is the dominant factor.

In the case of the same staggered distance $h$, the larger diameter of the extruded profile $D_{2}$ is, the smaller curvature $\kappa$ is, which is proportional to curvature $\kappa$ and extrusion ratio $\lambda$, as shown in Fig. $9 \mathrm{~b})$. When the extrusion ratio $\lambda$ increases from 11.11 to 44.44 , the curvature $\kappa$ changes from 0.0546 to 0.1607. Compared with the influence of staggered distance $h$ on curvature, the influence of extrusion ratio on curvature $\kappa$ is more significant.
Through the comparison, it can be seen that the FE modelling and experimental results are in good agreement, and the theoretical value is consistent with the FE modelling and experimental results, but the value is slightly larger.

\section{Conclusions}

1. Herein, the theoretical model of extrusion load and curvature change of AZ31 magnesium alloy was established by dividing the billet into different zones during the SE process and calculating the upper power consumption of each zone. Among them, eccentricity ratio $\xi$ is an important parameter in the theoretical model. The combination matching of different staggered distance $h$ and extrusion ratio $\lambda$ can correspond to an eccentricity ratio $\xi$. Eccentricity ratio $\xi$ decreases with the increase of 
staggered distance $h$ or extrusion ratio $\lambda$. Compared with staggered distance $h$, the change of extrusion ratio $\lambda$ has more influence on eccentricity ratio $\xi$;

2. Different from the traditional extrusion process, the load variation of SE can be divided into four distinct characteristic stages, including upsetting, extrusion of billet from die, filling completely and steady-state extrusion. With the increase of the staggered distance $h$, the time to reach the peak value of the ultimate load is relatively delayed, that is, the peak value of the ultimate load of SE appears earlier when the staggered distance $h$ is small. The staggered distance $h$ increased makes the peak value of ultimate load decreases;

3. The experimental results show that when the staggered distance $h=8 \mathrm{~mm}$ and the extrusion ratio $\lambda$ is 11.11 , the curvature $\kappa$ is 0.0546 . Under the condition that $\lambda=11.11$ and $h=24 \mathrm{~mm}$, the curvature $\kappa$ increases to 0.0971 . As the staggered distance $h$ is constant and the extrusion ratio $\lambda$ is 44.44 , the curvature $\kappa$ is greatly increased to 0.1607 , which can be seen that the influence of extrusion ratio on curvature $\kappa$ is greater. The model was verified by FE modelling and process experiment. It is found that the overall change trend of the theory, FE modelling and process experiment is consistent, but the theoretical value is slightly greater than the two.

\section{Ethics declarations}

\section{Ethical Approval}

Not applicable

\section{Consent to Participate}

Not applicable

\section{Consent to Publish}

Not applicable

\section{Authors Contributions}

Staggered extrusion process is a new method for bending products forming integrated. The theoretical model established by upper bound method lays a foundation for controlling the bending products curvature.

\section{Funding information}

This project is supported by National Natural Science Foundation of China (No. 51975166).

\section{Competing Interests}

Not applicable

\section{Availability of data and materials}

The data obtained in the framework of this study are available to the journal upon request.

\section{References}

1. Hasegawa O, Manabe K, Murai T (2014) Stretch Press Bending of AZ31 Magnesium Alloy Extruded Square Tube. Procedia Engineering 81: 2184-2189

2. Ren WJ, Li JJ, Xin RL (2019) Texture dependent shifting behavior of neutral layer in bending of magnesium alloys. Scripta Materialia 170: 6-10

3. Shi YJ, Guo YK, Wang XG, Sun R, Li XF (2021) Laser bending angle and surface quality with preload at low heating temperature. Optics \& Laser Technology 136: 106755

4. Murata M (1996) Effects of Inclination of Die and Material of Circular Tube in MOS Bending Method. Transactions of the Japan Society of Mechanical Engineers 62(601):3669-3675

5. Chatti S, Hermesm M, Tekkaya AE, Kleiner M (2010) The new TSS bending process: 3D bending of profiles with arbitrary cross-sections. CIRP Annals 59(1):315-318

6. Müller KB (2006) Bending of Extruded Profiles during Extrusion Process. International Journal of Machine Tools \& Manufacture 46(11):1238-1242

7. Shiraishi M, Nikawa M, Goto Y (2003) An 
investigation of the curvature of bars and tubes extruded through inclined dies. International Journal of Machine Tools and Manufacture 43(15): 1571-1578

8. Shiraishi M, Nikawa M, Kubota T, Goto Y (2007) Prediction of curvatures of parts extruded through rotary die using fuzzy inference. Journal of Materials Processing Technology 187-188:702-705

9. Takahashi Y, Kihara S, Yamaji K, Shiraishi M (2015) Effects of Die Dimensions for Curvature Extrusion of Curved Rectangular Bars. Materials Transactions 56(6):954-958

10. Zhou WB, Lin JG, Dean TA, Wang LL (2017) A novel application of sideways extrusion to produce curved aluminium profiles: Feasibility study. Procedia Engineering 207: 2304-2309

11. Zhou WB, Lin JG, Dean TA, Wang LL (2018) Feasibility studies of a novel extrusion process for curved profiles: Experimentation and modelling. International Journal of Machine Tools and Manufacture 126: 27-43

12. Zhou WB, Yu JQ, Lin JG, Dean TA (2019) Manufacturing a curved profile with fine grains and high strength by differential velocity sideways extrusion. International Journal of Machine Tools and Manufacture 140: 77-88

13. Zhou WB, Yu JQ, Lin JG, Dean TA (2020) Effects of die land length and geometry on curvature and effective strain of profiles produced by a novel sideways extrusion process. Journal of Materials Processing Technology 282: 116682

14. Zhou WB, Lin JG, Dean TA, Wang LL (2018) Analysis and modelling of a novel process for extruding curved metal alloy profiles. International Journal of Mechanical Sciences 138-139: 524-536

15. Zhou WB, Shi ZS, Lin JG (2018) Upper bound analysis of differential velocity sideways extrusion process for curved profiles using a fan-shaped flow line model. International Journal of Lightweight Materials and Manufacture 1(1): 21-32
16. Wang YP, Li F, Shi WY, Li XW, Fang WB (2019) Microstructure, bending behavior and texture evolution of AZ31B magnesium alloy bending products processed by staggered extrusion (SE). Materials Characterization 155(9):109842

17. Wang YP, Li F, Wang Y, Li XW, Fang WB (2020) Effect of extrusion ratio on the bending behavior, microstructure and texture evolution of AZ31 magnesium alloy by the staggered extrusion (SE). Journal of Magnesium and Alloys 8(4): 1304-1313

18. Wang YP, Li F, Shi WY, Li XW, Fang WB (2019) Dynamic Recrystallization and Metal Flow Behavior of AZ31 Magnesium Alloy Bending Products Processed by Staggered Extrusion. Journal of Materials Engineering and Performance 28(6): 3551-3559

19. Li H, Li SY, Zhang DH (2010) On the selection of outlet channel length and billet length in equal channel angular extrusion. Computational Materials Science 49(2): 293-298.

20. Kazanowski P, Browne HM, Libura W, Misiolek WZ (2005) Mechanical and microstructural performance of convex dies in axisymmetric extrusion-theory and experimental verification. Materials Science \& Engineering A 404(1-2): 235-243.

21. Altinbalik T, Ayer O (2013) Effect of die inlet geometry on extrusion of clover sections through curved dies: Upper bound analysis and experimental verification. Transactions of Nonferrous Metals Society of China 23(4): 1098-1107.

22. Chen L, Zhang JX, Tang JW, Chen GJ, Zhao GQ, Zhang CS (2018) Microstructure and texture evolution during porthole die extrusion of Mg-Al-Zn alloy. Journal of Materials Processing Technology 259: 346-352.

\section{Publisher's note}

Springer Nature remains neutral with regard to jurisdictional claims in published maps and institutional affiliations. 

Figures

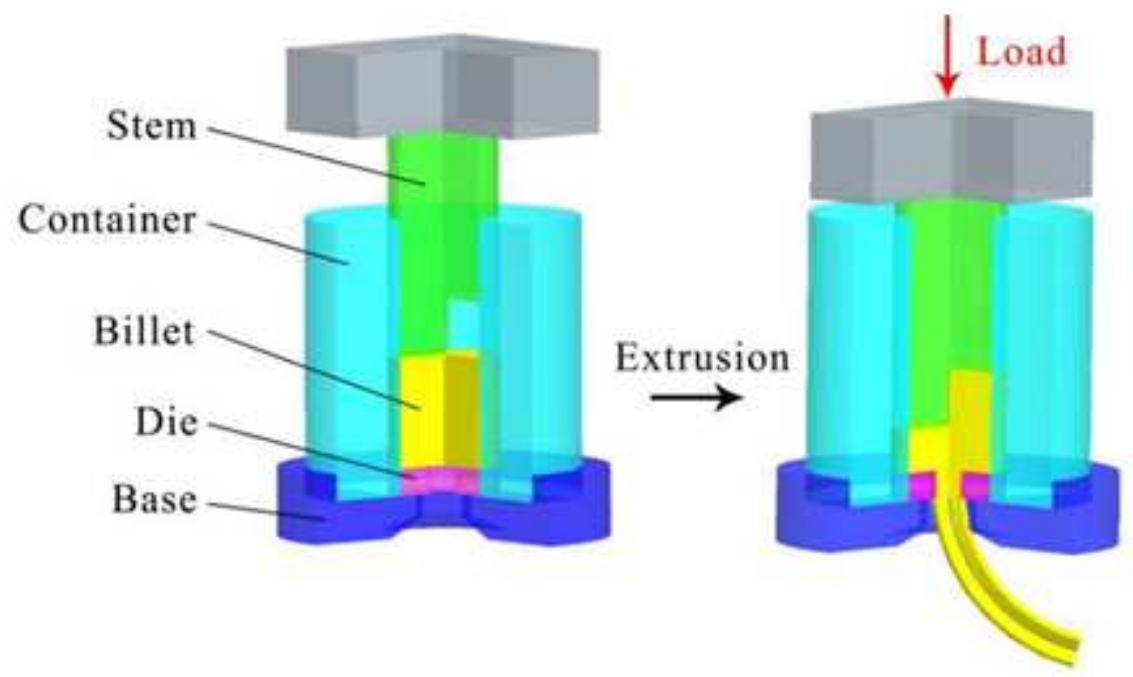

Figure 1

The schematic diagram of the SE process 


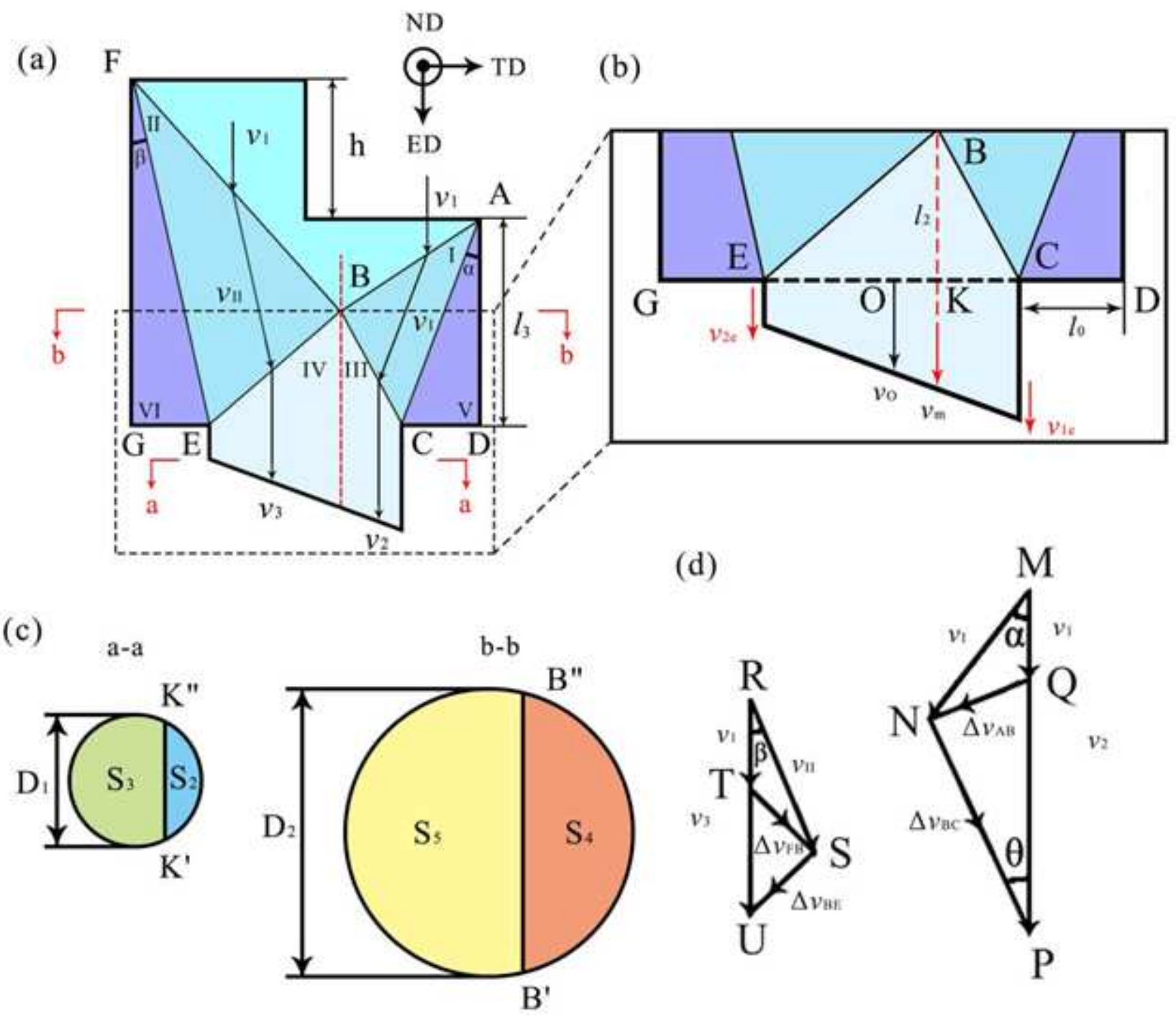

Figure 2

The two dimensional model of the SE process: a) zone division of deformation b) model details in zones $\mathrm{III}$ and $\mathrm{V} \mathrm{C}$ ) the projection of BB" into the related profile of the die and billet d) the related hodograph 


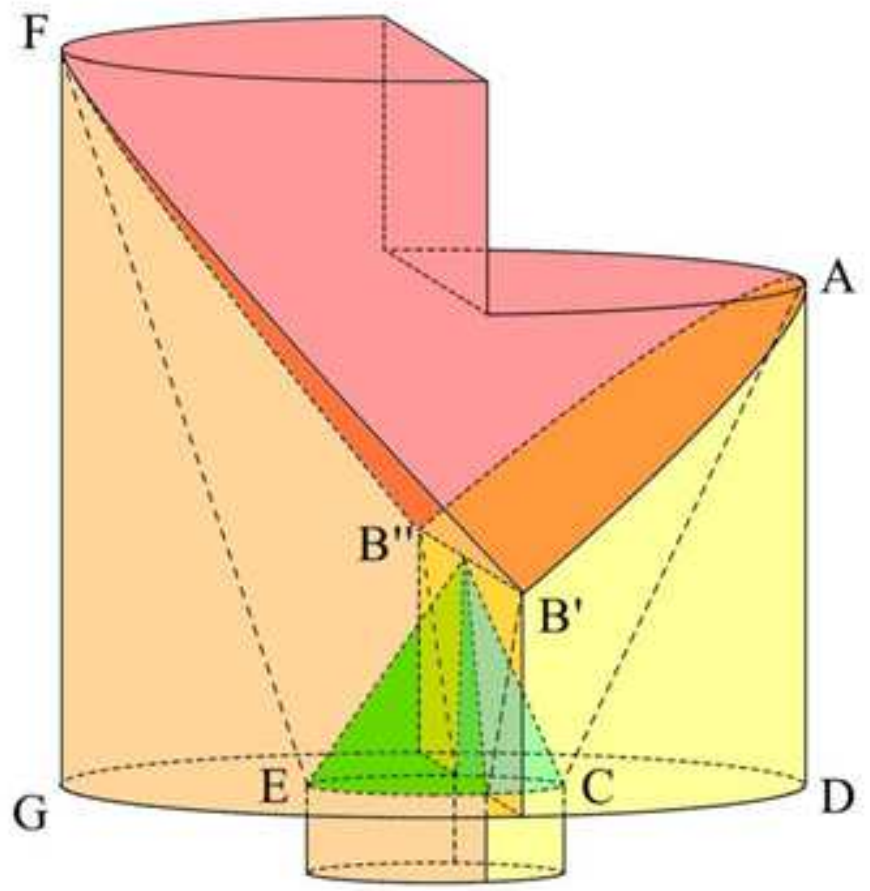

Figure 3

The three dimensional model of velocity discontinuity of the SE process

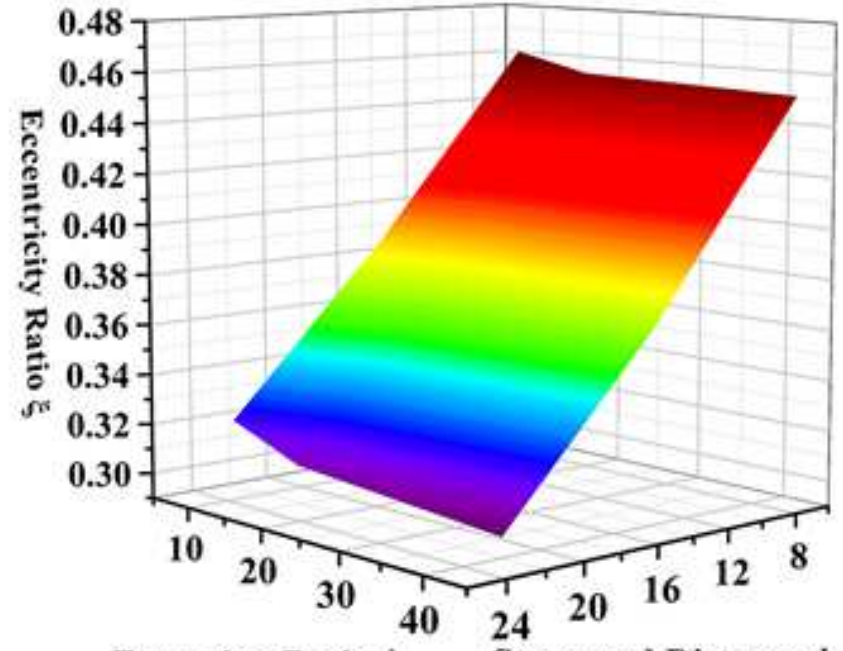

Extrusion Ratio $\lambda \quad$ Staggered Distance $h / \mathrm{mm}$

(a)

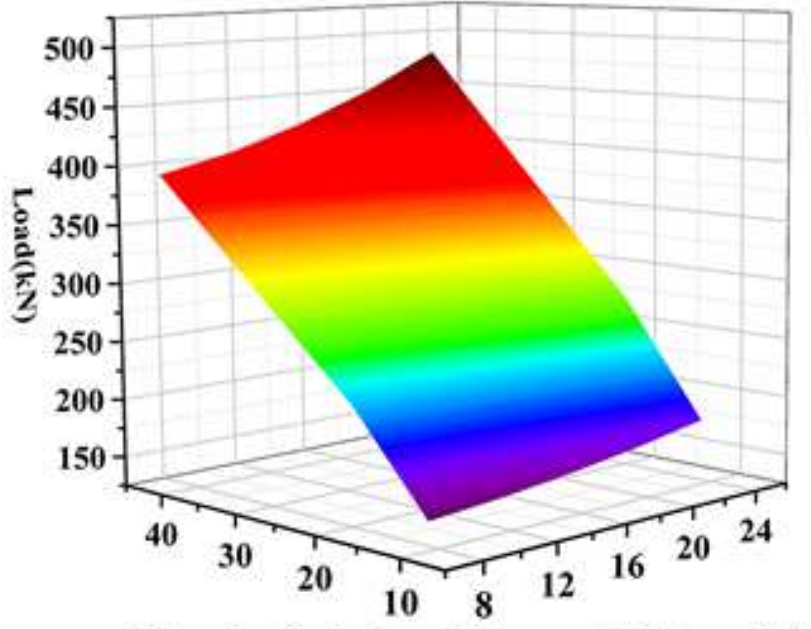

Extrusion Ratio $\lambda \quad$ Staggered Distance $h / \mathrm{mm}$ (b)

\section{Figure 4}

The relationship between the parameters: a) the relationship among eccentricity ratio $\xi$, staggered distance $h$ and extrusion ratio $\lambda \mathrm{b}$ ) relationship between load and extrusion ratio $\lambda$ and staggered distance $h$ 


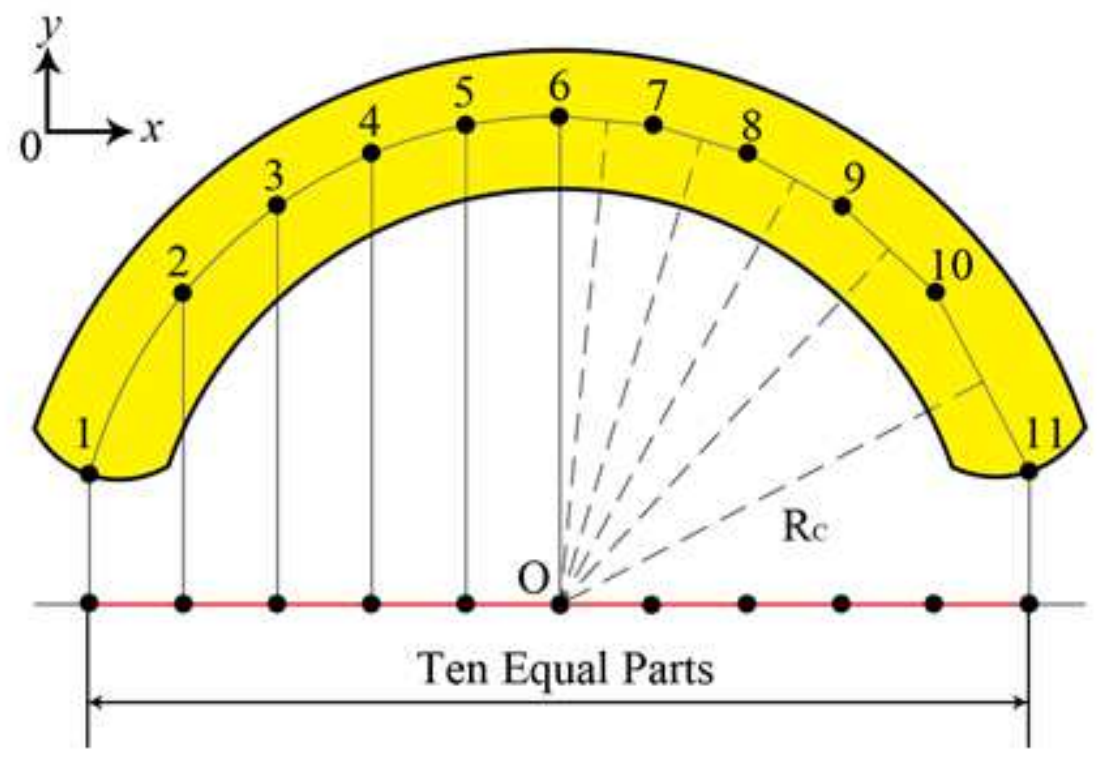

Figure 5

Point selection and curvature calculation

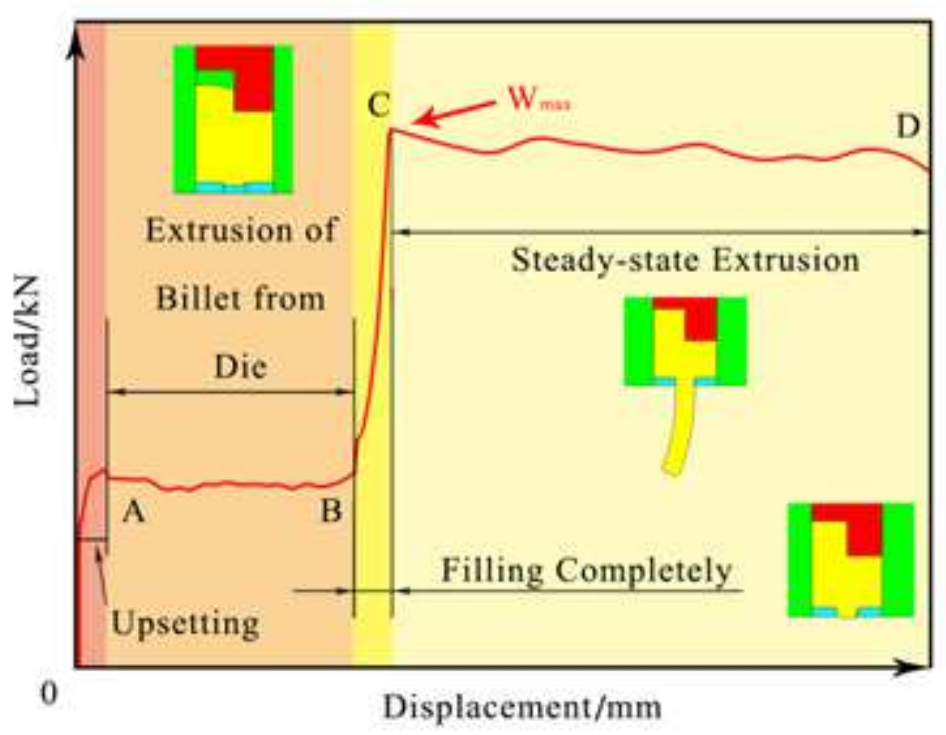

Figure 6

Displacement-load relationship in SE 


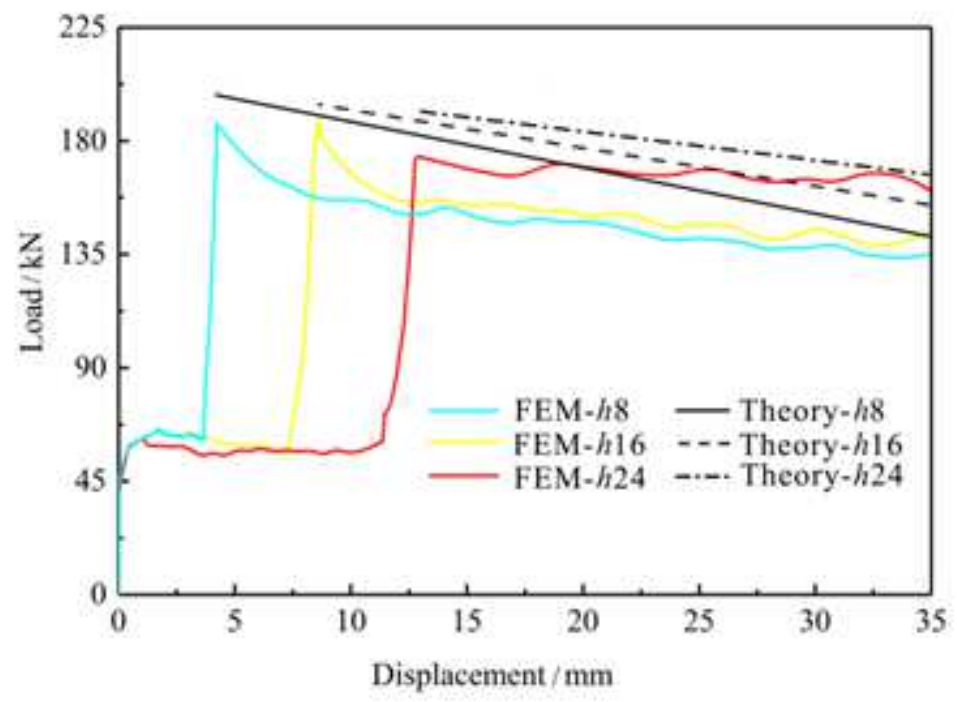

Figure 7

the comparison of FE modelling and theory of load in $\lambda=11.11, \mathrm{~h}=8 \mathrm{~mm}, 16 \mathrm{~mm}$ and $24 \mathrm{~mm}$ respectively

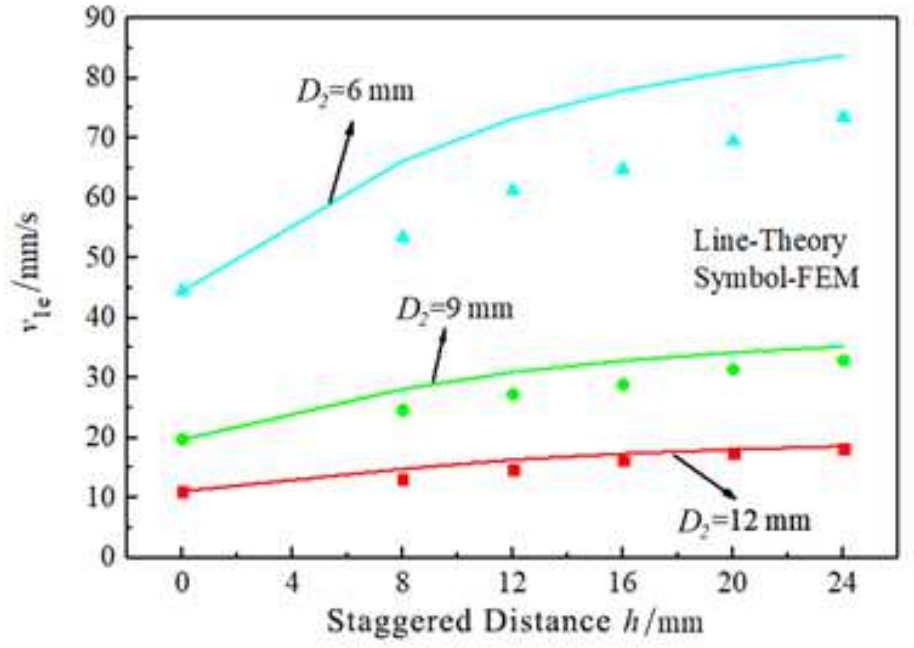

(a)

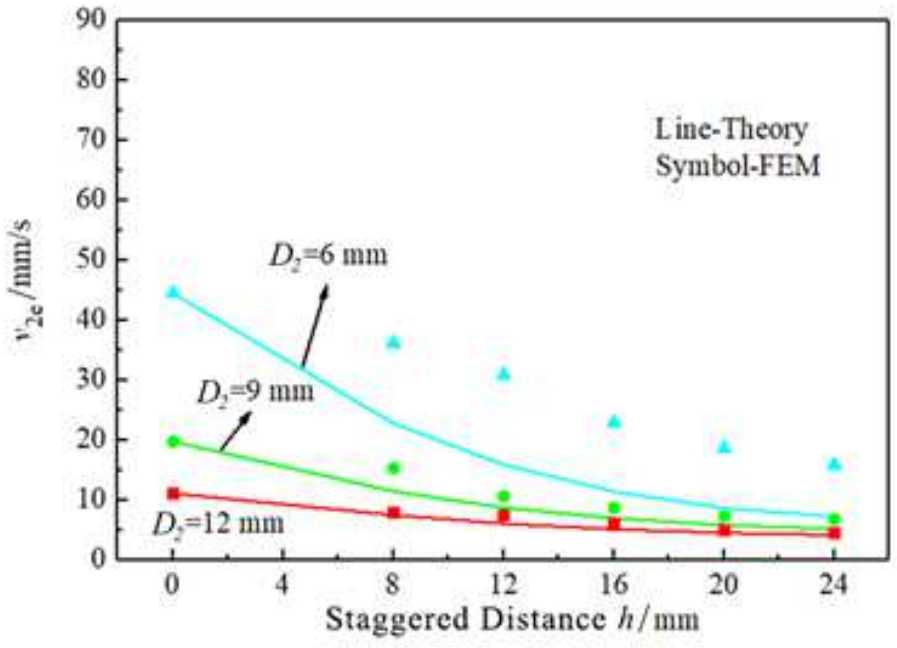

(b)

\section{Figure 8}

Comparison of velocity extremes at die exit: a) maximum velocity b) minimum velocity 


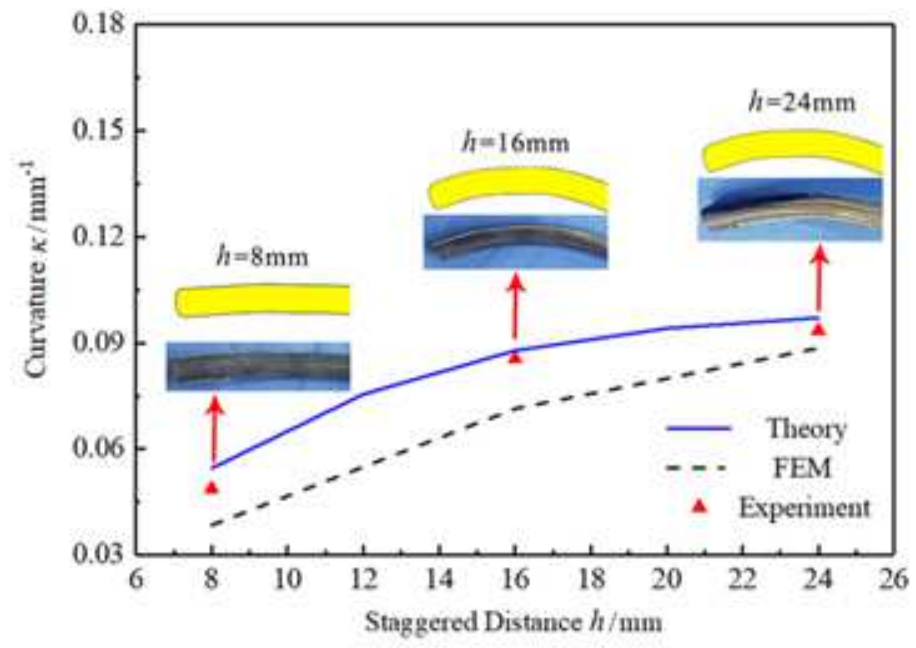

(a)

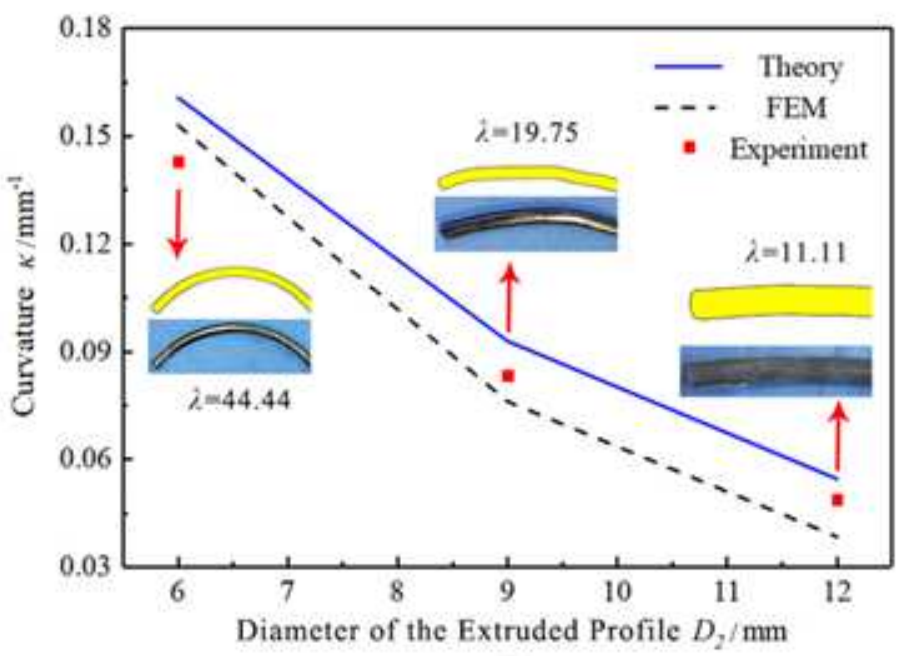

(b)

\section{Figure 9}

The relationship between staggered distance $h$, diameter of the extruded profile D2 and curvature $\mathrm{k}: \mathrm{a}$ ) staggered distance $\mathrm{h}$ b)diameter of the extruded profile D2 